\title{
Frontiers in Social Pediatrics: AK Patwari, HPS Sachdev (eds)
}

\author{
Published by Jaypee Brothers Medical Publishers (P) Ltd, New Delhi, Second Edition, 2016; \\ ISBN: 978-93-85891-66-3; Pages: 442
}

\author{
B. D. Gupta ${ }^{1}$
}

Received: 30 May 2016/Accepted: 30 May 2016 / Published online: 10 June 2016

(C) Dr. K C Chaudhuri Foundation 2016

Social Pediatrics or the Community Pediatrics basically focuses on the health needs of children in the context of ground reality of a society or the country. It encompasses the health status of children, their morbidity, mortality and the various programs for the needs of this special segment of the population. Frontiers in Social Pediatrics, a multi authored book, edited by Dr. A.K. Patwari and Dr. HPS Sachdev is a welcome step in this direction. This edition comprises of seven sections viz. Evolution of social pediatrics in India; Neonatal, child and adolescent health; Nutrition; Everyday practice; Legal rights and vulnerable children; Clinical epidemiology and research and National health programs.

The social and environmental factors related to child health have been described in details from neonatal period through adolescence. All the national programs for the improvement of the health of children have been described at length. The IAP guidelines for treatment of certain specific diseases have been given and the

B. D. Gupta

brahmadgupta@hotmail.com

Department of Pediatrics, Regional Institute of Maternal \& Child Health, Umaid Hospital, Dr. S.N. Medical College, Jodhpur, India good part is that these guidelines have been described vis a vis to WHO guidelines which give the book an international status. Preventive strategies for communicable diseases by various means including immunization and for non communicable diseases are well described. The Section on nutrition emphasizes the need for good nutrition in childhood and recent growth charts (2015) have been included for assessment of nutritional status in children. Importance of infant and young child feeding practices has been highlighted but a separate chapter on BFHI (Baby Friendly Hospital Initiative) and role of BPNI (Breast feeding Promotion Network of India) would have been a welcome step. Again, a chapter on neonatal and infant morbidity and mortality and their prevention would have been a significant addition. Legal rights of vulnerable children and chapters on child labor and child abuse and neglect add to the importance of the book. However, there are repetition at many places, for example, childhood HIV in chapters 9 and 37 and growth charts in chapters 14 and 15, which could have been avoided. Overall, this book is a good volume related to social and preventive pediatrics which will be useful to all the postgraduates and teachers of pediatrics and community medicine, research scholars and the policy makers not only of India but also of other developing countries. 